\title{
FORMULAÇÃO DO BIOSSURFACTANTE PRODUZIDO POR CANDIDA LIPOLYTICA PARA APLICAÇÃO NA REMOÇÃO DE POLUENTES AMBIENTAIS GERADOS PELA INDÚSTRIA DE PETRÓLEO CONTIDOS EM ÁGUA DO MAR
}

\author{
H. S. AMORIM ${ }^{1}$, J. G. M. BRITO ${ }^{2}$, P. F. CORREAA ${ }^{3}$, R. D. RUFINO ${ }^{4}$, J.M. LUNA ${ }^{5}$, L.A. \\ SARUBBO $^{6}$
}

${ }^{1}$ Universidade Católica de Pernambuco, Departamento de Engenharia Química

E-mail para contato: henrique.siqueira.amorim@gmail.com

\begin{abstract}
RESUMO - A recuperação da poluição por derramamentos de óleo é atualmente a preocupação das indústrias. Uma das alternativas para remediar a contaminação por compostos hidrofóbicos consiste na aplicação de biossurfactante. Nesse sentido, foi realizada a produção de biossurfactante por Candida lipolytica cultivada em meio mineral, $6 \%$ do resíduo de óleo vegetal e $1 \%$ de ácido glutâmico, durante 72 horas e $200 \mathrm{rpm}$. O biossurfactante produzido foi adicionado ao conservante comercial a fim de testar sua estabilidade frente a diferentes variações de $\mathrm{pH}$, temperatura e sal. Em seguida o líquido metabólico, foi estocado à $28{ }^{\circ} \mathrm{C}$ por 120 dias, onde foram realizados testes de tensão superficial e índice de emulsificação. Os resultados obtidos demonstraram estabilidade na tensão superficial frente às variações de $\mathrm{pH}$, temperatura $\mathrm{e}$ salinidade. Os melhores percentuais do índice de emulsificação foram para o óleo de motor. A biomolécula apresentou potencial para aplicação como agente de remediação ambiental.
\end{abstract}

\section{INTRODUÇÃO}

A liberação de contaminantes, tais como petróleo e derivados para o meio ambiente é uma das principais causas da poluição global (Saeki et al., 2009). Os acidentes ocorridos com derramamentos de petróleo e seus derivados, como o ocorrido no Brasil, no período de 1975 a 2005 que atingiram milhões de litros e causaram a contaminação de solos, rios e mares, torna real e iminente a contaminação ambiental, havendo necessidade de aplicação de tecnologias que possam conter possíveis contaminações (Silva et al., 2010).

A necessidade em remediar áreas contaminadas levou ao desenvolvimento de novas tecnologias que possibilitem a detoxificação destes contaminantes de forma não 
convencional, ou seja, sem a utilização de métodos meramente químicos ou físicos. O uso de micro-organismos ou produtos microbianos para degradar compostos poluentes, é uma destas novas tecnologias, chamada de biorremediação (Fracchia et al., 2012). É descrito por Calvo et al. (2009) como um processo de estimulação natural de micro-organismos na biodegradação de óleos e no tratamento de ambientes terrestres e aquáticos contaminados com compostos xenobióticos.

Os compostos de origem microbiana que exibem propriedades surfactantes, isto é, diminuem a tensão superficial, oriunda das forças intermoleculares da água e possuem alta capacidade emulsificante, que é responsável por agregar moléculas a outras diferentes, são denominados biossurfactantes (Franzetti, 2010). Em comparação com os surfactantes sintéticos, os biossurfactantes apresentam uma toxicidade inferior, maior biodegradabilidade e compatibilidade ambiental, permitindo uma grande variedade de aplicações industriais que envolvem a detergência, a emulsificação, a lubrificação, a capacidade de formação de espuma, a molhabilidade, solubilização e a dispersão (Luna et al., 2013).

Nesse sentido, os resíduos industriais têm despertado grande interesse dos pesquisadores como substratos de baixo custo para a produção de biossurfactantes. Óleos vegetais, resíduos de fritura de óleos vegetais, resíduos de destilaria de óleos, resíduos da indústria de laticínios (soro de leite), melaço de cana e glicerina têm sido citados na literatura (Tuleva et al., 2002). Luna et al. (2013), Coimbra et al. (2009) e Rufino et al. (2008) utilizaram resíduos industriais na produção de biossurfactantes, obtendo resultados satisfatórios em termos de tensão superficial.

Pattanath e colaboradores (2008) sugerem quatro fatores para a redução dos custos dos biossurfactantes: (1) os micro-organismos, (2) o processo, (3) o meio de cultura e (4) o processamento de produtos reciclados. Assim, a aplicação de biossurfactantes na recuperação avançada de petróleo depende da sua estabilidade em condições extremas de temperatura, salinidade e de $\mathrm{pH}$, ou atividades em superfície. Muitos desses fatores ambientais podem influenciar as propriedades físico-químicas de um biossurfactante (JOSHI et al., 2008).

Dessa forma, o presente trabalho teve como principal objetivo formular e estudar a estabilidade do biossurfactante produzido pela Candida lipolytica UCP0988 em meio de baixo custo, com vistas à aplicação dessa biomolécula como aditivo coadjuvante em processos de remediação de poluentes hidrofóbicos gerados pela indústria de petróleo.

\section{MATERIAL E MÉTODOS}

\subsection{Micro-organismo}


A levedura do gênero Candida lipolytica UCP0988, depositada no Banco de Culturas do Núcleo de Pesquisas em Ciências Ambientais da UNICAP, foi utilizada como microorganismo produtor de biossurfactante. As culturas foram mantidas em tubos de ensaio inclinados em meio Yeast Mold Ágar (YMA), contendo: extrato de levedura (0,3\%); Dglicose $(1,0 \%)$; Triptona $(0,5 \%)$; Ágar $(2,0 \%)$; Extrato de malte $(0,3 \%)$, sob refrigeração a $5^{\circ} \mathrm{C}$, sendo repicadas a cada 30 dias.

\subsection{Produção do Biossurfactante}

O biossurfactante foi produzido em meio mineral contendo resíduos industriais como substratos (Rufino et al., 2008).

\subsection{Preparação do Inóculo}

O inóculo das leveduras foi padronizado, transferindo-se as culturas para um tubo contendo o meio YMA, a fim de se obter uma cultura jovem. Em seguida, a amostra foi transferida para frascos contendo $50 \mathrm{~mL}$ do meio Yeast Mold Broth (YMB) e incubados sob agitação de $200 \mathrm{rpm}$ a $28^{\circ} \mathrm{C}$ durante 24 horas.

\subsection{Conservação do Líquido Metabólico Contendo o Biossurfactante}

Para conservação do líquido metabólico (centrifugado e filtrado a vácuo e por gravidade) contendo o biossurfactante utilizou-se $0,2 \%$ de sorbato de potássio. Em seguida, o líquido metabólico com conservante foi estocado à temperatura ambiente durante 120 dias para observação da estabilidade do biopolímero. Testes foram realizados para determinação do tempo $\left(0,15,30,45,90\right.$ e 120 dias) e temperatura $\left(28-30^{\circ} \mathrm{C}\right)$. Em cada intervalo de tempo foram determinadas: tensão superficial, capacidade de emulsificação e dispersão/agregação de composto hidrofóbico em água do mar.

\subsection{Determinação das Atividades de Emulsificação}

Para a determinação das atividades de emulsificação, amostras dos líquidos metabólicos livre de células dos biossurfactantes formulados foram analisadas segundo a metodologia descrita por Cooper e Goldenberg (1987): 1,0 mL de um substrato oleoso (petróleo, óleo de soja e óleo de milho) foram adicionados a 1,0 mL do líquido metabólico em tubo de ensaio e a mistura foi agitada em vórtex por 1 minuto. Após 24 horas, as emulsões água em óleo foram expressas em centímetros, devido à altura da emulsificação formada.

\subsection{Determinação da Tensão Superficial}

A tensão superficial do líquido metabólico, livre de células, do biossurfactante formulado foi medida em tensiômetro KSV Sigma 700 (Finland) utilizando-se o anel de NUOY. A tensão superficial foi medida através da imersão do anel de platina no líquido metabólico e registrando-se a força requerida para puxá-lo através da interface ar-líquido. 


\subsection{Avaliação da Estabilidade do Biossurfactante (Efeitos do pH, da Adição de $\mathrm{NaCl}$ e da Temperatura)}

A estabilidade do biossurfactante também foi testada em diferentes temperaturas (40 e $50^{\circ} \mathrm{C}$ ) durante 30 minutos, diferentes concentrações de $\mathrm{NaCl}(1,3$ e $5 \%)$, e diferentes valores de $\mathrm{pH}(5,7$ e 9). Após essa etapa foram determinadas as atividades emulsificantes e tensoativas do biossurfactante formulado. Os testes determinaram a tensão superficial, a atividade de emulsificação e o teste de dispersão. Todas as análises foram realizadas em triplicata.

\subsection{Experimentos de Deslocamento (Dispersão/Agregação) de Composto Hidrofóbico em Água do Mar}

A capacidade de dispersão ou agregação de manchas de derivados de petróleo foi simulada em laboratório, contaminando-se amostras de água do mar com óleo de motor. Os testes foram realizados pela adição de $20 \mu \mathrm{L}$ do biossurfactante formulado, nas proporções de 1:2, 1:8 e 1:25 (v/v) em óleo motor. Os resultados foram observados visualmente.

\section{RESULTADOS E DISCUSSÃO}

\subsection{Determinação da Tensão Superficial do Biossurfactante Frente à Adição de Sorbato de Potássio}

A Figura 1 apresenta os resultados obtidos referentes à avaliação da estabilidade da tensão superficial do líquido metabólico contendo o biossurfactante produzido por Candida lipolytica.

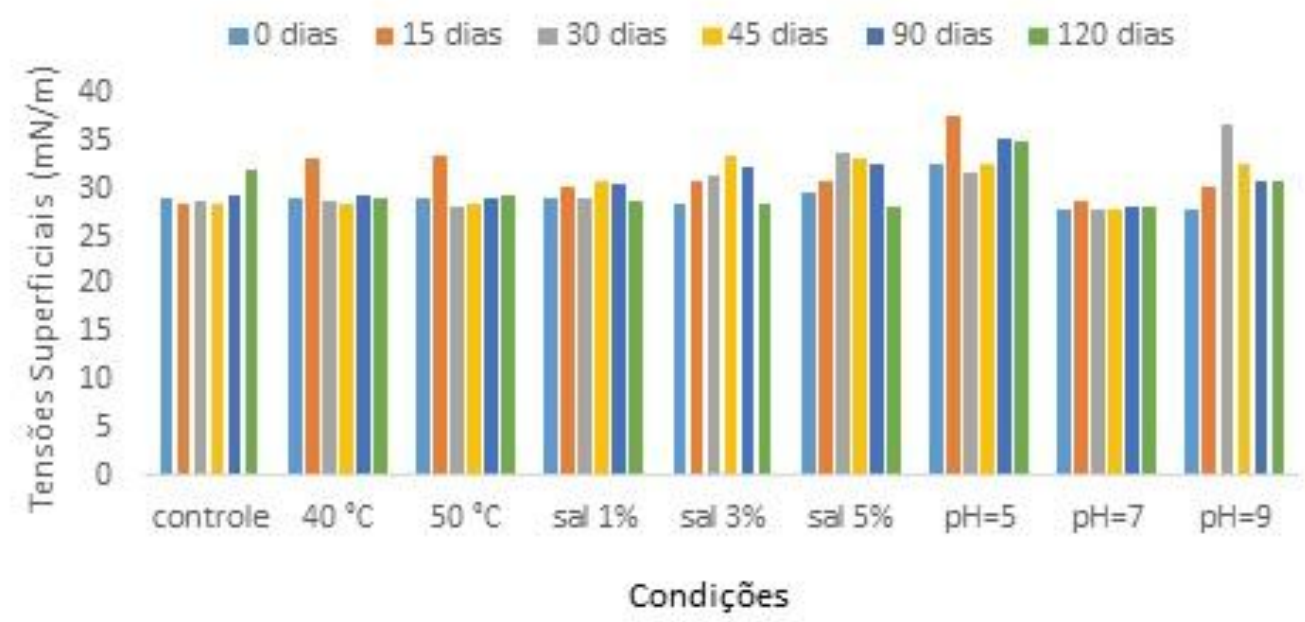

Figura 1 - Tensões superficiais do biossurfactante produzido por Candida lipolytica. 
O biossurfactante formulado na condição controle $\left(28^{\circ} \mathrm{C}\right.$, ausência de $\mathrm{NaCl}$ e pH 6,0) apresentou uma tensão superficial de $28,46 \mathrm{mN} / \mathrm{m}$. Ao longo dos 120 dias do experimento, de um modo geral, pode-se observar que houve estabilidade no valor da tensão superficial frente as variações de $\mathrm{pH}$, temperatura e salinidade, já que as tensões permaneceram com valores em torno de $30 \mathrm{mN} / \mathrm{m}$. Após quinze dias de experimento houve um aumento na tensão superficial e que com o decorrer do tempo esse valor voltou a reduzir. Com relação à variação de $\mathrm{pH}$, os melhores valores de tensão superficial foram verificados em pH neutro $(25-30 \mathrm{mN} / \mathrm{m})$.

Os resultados obtidos são comparáveis aos observados em estudos realizados por Nitschke et al. (2004), no qual micro-organismos foram selecionados para a produção de biossurfactantes utilizando resíduos agroindustriais como substratos, os valores de tensão superficial permaneceram em torno de $27 \mathrm{mN} / \mathrm{m}$.

\subsection{Determinação da Atividade de Emulsificação do Biossurfactante Frente à Adição de Sorbato de Potássio}

A Figura 2 apresenta os percentuais de emulsificação de diferentes compostos hidrofóbicos pelo biossurfactante adicionado do conservante sorbato de potássio.
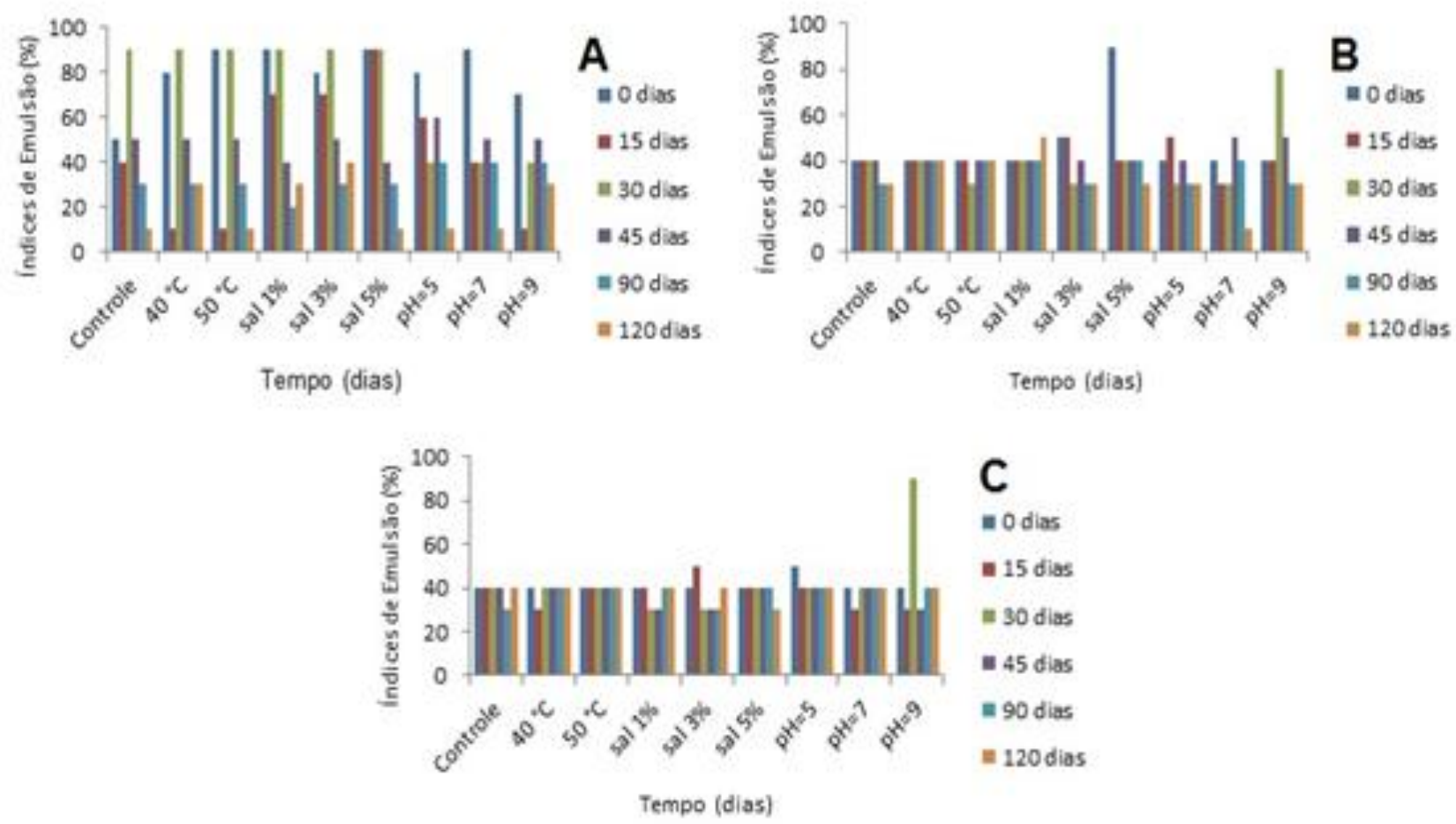

Figura 2 - Capacidade de emulsificação de óleo de motor (A), óleo de milho (B) e óleo de soja (C) pelo biossurfactante de Candida lipolytica adicionado de sorbato de potássio.

Os resultados observados para atividade de emulsificação do óleo de motor (Figura 2A) apresentaram valores satisfatórios, visto que valores de 50 a $90 \%$ foram observados para todos os parâmetros testados. Após trinta dias, uma maior atividade de emulsificação, com valores a partir de $90 \%$ foi observada. Quando os líquidos metabólicos contendo o 
biossurfactante conservado com sorbato de potássio foram submetidos a temperaturas entre 40 e $50^{\circ} \mathrm{C}$ as atividades de emulsificação permaneceram estáveis com valores em torno de $90 \%$.

As emulsões formadas com os óleos vegetais de milho e soja, ilustrados respectivamente na Figura 2 (B) e (C), apresentaram resultados inferiores em relação ao óleo de motor, com atividades de emulsificação em torno de 50\%. No pH 9,0 observou-se um aumento nos percentuais de emulsificação desses óleos após trinta dias de experimento. Em seguida, esses valores diminuíram mantendo-se novamente na faixa de 50\%. Os resultados apresentados são comparáveis aos observados por Brasileiro et al. (2013) onde valores de $25,9 \%$ foram obtidos para o óleo de soja e $100 \%$ para o óleo de motor.

\subsection{Dispersão do Óleo de Motor pelo Biossurfactante Conservado com $\underline{\text { Sorbato de Potássio }}$}

Os resultados de dispersão obtidos para o biossurfactante formulado com sorbato de potássio submetido a variações de temperatura, salinidade e $\mathrm{pH}$ em diferentes proporções de 1:2, 1:8, 1:25 (v/v) (surfactante/óleo de motor) durante 120 dias, estão ilustrados nas Figuras 3 (A), (B) e (C), respectivamente.

Os maiores percentuais de dispersão foram observados quando o biossurfactante foi aplicado na maior proporção em relação ao óleo, como pode ser verificado na Figura 3 (A) onde apresentou dispersões de até $45 \%$. Observou-se também, que o tempo de prateleira de 120 dias favoreceu a capacidade dispersante do biossurfactante, já que dispersões de $40 \%$ foram observadas para as três diferentes concentrações testadas em todos os parâmetros analisados.

Considerando os inúmeros parâmetros avaliados, pode-se observar que a temperatura de $40^{\circ} \mathrm{C}$ favoreceu a dispersão do óleo de motor, possibilitando a utilização futura do biossurfactante em ambientes com temperaturas elevadas. A faixa neutra de $\mathrm{pH}$ também exerceu uma influência positiva, enquanto que a presença de elevadas concentrações salinas não foram favoráveis à propriedade dispersante do biossurfactante formulado. 

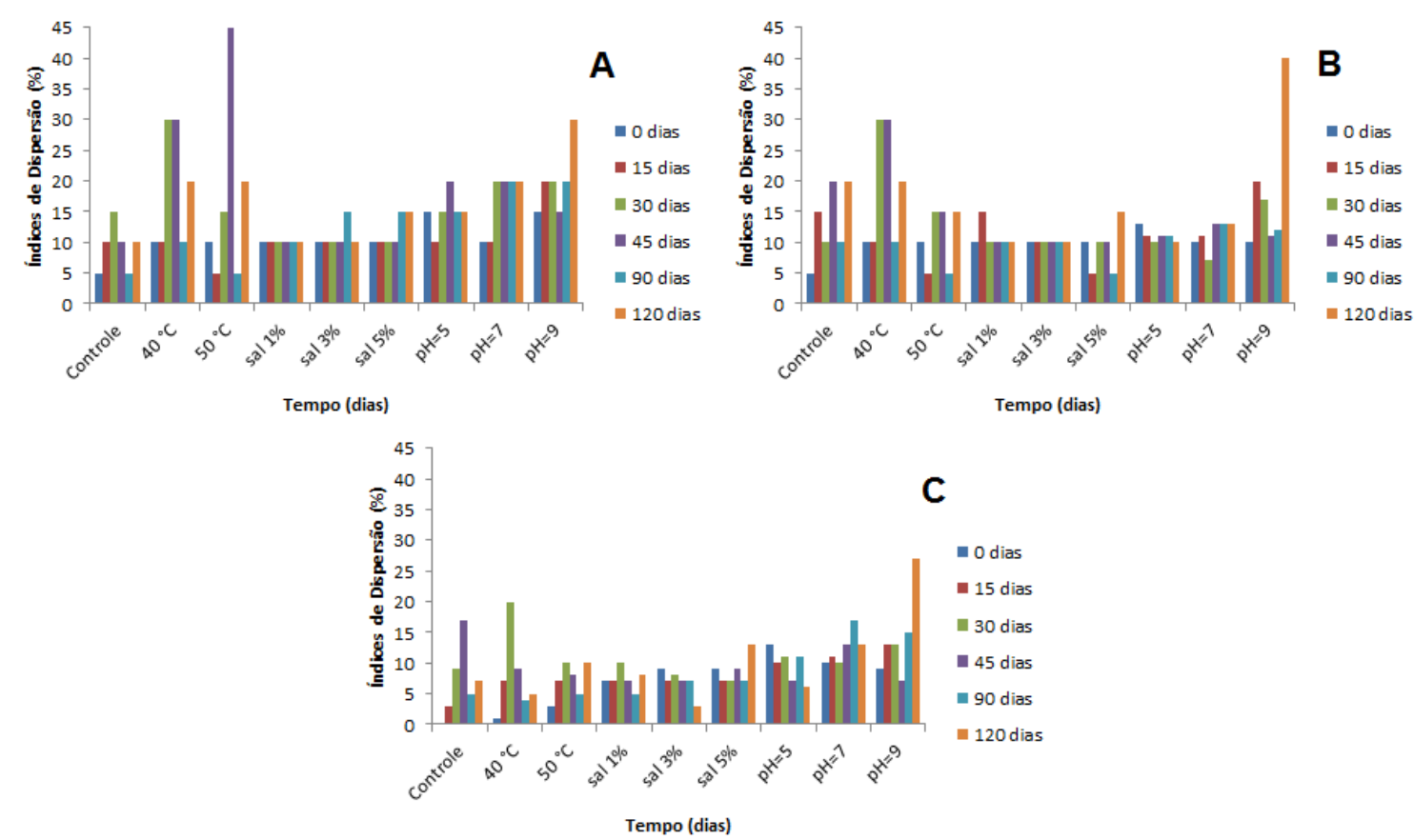

Figura 3 - Capacidade de dispersão do óleo de motor pelo biossurfactante produzido por Candida lipolytica adicionado de sorbato de potássio na proporção 1:2 (A), 1:8 (B) e 1:25 (C).

\section{CONCLUSÃO}

O biossurfactante produzido pela Candida lipolytica e formulado com Sorbato de Potássio, apresentou a conservação de suas propriedades básicas como a capacidade de redução da tensão superficial e a emulsificação de óleo de motor. Dessa forma, pode-se sugerir seu potencial de utilizações futuras, como agente de remediação ambiental.

\section{REFERÊNCIAS}

BRASILEIRO, P.P.F.; SOUZA FILHO, G.L.; SILVEIRA, G.N.M.; ROCHA E SILVA, N.M.P.; CAMPOS, J.M.; LUNA, J.M.; RUFINO, R.D.; SANTOS, V.A.; SARUBBO, L.A. Estudo da estabilidade do biossurfactante produzido em biorreator para biorremediação. In: I Congresso Internacional de Ciências Biológicas, II Congresso Nacional de Ciências Biológicas e VI Simpósio de Ciências Biológicas. 2013.

CALVO, C.; MANZANERA, M.; CASTRO, G.A.S.; LOPE'Z J.G. Application of bioemulsifiers in soil oil bioremediation processes. Future prospects. Sci Total Environ v. 407, p. $3634-3640,2009$.

COIMBRA, C.D.; RUFINO, R.D.; LUNA, J.M.; SARUBBO, L.A. Studies of the cell surface properties of Candida species and relation to the production of biosurfactants for environmental applications. Curr. Microbiol. 58, p. 245-251, 2009.

FRACCHIA, L.; CAVALLO, M.; GIOVANNA MARTINOTTI; M., BANAT, I.M. Biosurfactants and bioemulsifiers biomedical and related applications - Present Status 
and Future Potentials, Biomedical Science, Engineering and Technology. Dhanjoo N. Ghista (Ed.), v. 14, p. 325-370, 2012.

FRANZETTI, A.; GANDOLFI, I.; BESTETTI, G.; SMYTH, T.J.P.; BANAT, I.M. Production and applications of trehalose lipid biosurfactants. European Journal of Lipid Science and Technology. v. 112, p. 27-617, 2010.

JOSHI, S.; BHARUCHA, C.; JHA, S.; YADAV, S.; NERURKAR, A.; DESAI, A.J. Biosurfactant production using molasses and whey under thermophilic conditions. Bioresour. Technol. v. 99, p. 195-199, 2008.

LUNA, J.M.; RUFINO, R.D.; ALBUQUERQUE, C.D.C.; SARUBBO, L.A.; TAKAKI, G.G. C. Antimicrobial and anti-adhesive potential of a biosurfactant Rufisan produced by Candida lipolytica UCP 0988. Int. J. Mol. Sci. v. 84, p. 1-5, 2011.

LUNA, J.M.; RUFINO, R.D.; SARUBBO, L.A.; TAKAKI, G.M.C. Characterisation, surface properties and biological activity of a biosurfactant produced from industrial waste by Candida sphaerica UCP0995 for application in the petroleum industry. Colloids and Surfaces B: Biointerfaces, v. 102, p. 202-209, 2013.

PATTANATH, K. M.; RAHMAN, K. S.; GAKPE, E. Production, characterization and applications of biosurfactants - review. Biotechnology, v. 7, p.360-370, 2008.

RUFINO, R.D.; SARUBBO, L.A.; BENICIO, B.N.; TAKAKI, G.M.C. Experimental design for the production of tensio-active agent by Candida lipolytica. J.Ind. Microbiol. Biotechnol, v. 35, p. 907-914, 2008.

SAEKI, H.; SASAKI, K.M.; KOMATSU, O.; MIURA, A.; MATSUDA, H. Oil spill remediation by using the remediation agent JE1058BS that contains a biosurfactant produced by Gordonia sp strain JE-1058. Bioresour. Technol., v. 100, p. 572-577, 2009.

SILVA, S.N.R.L.; FARIAS, C.B.B.; RUFINO, R.D.; LUNA, J.M.; SARUBBO, L.A. Glycerol as substrate for the production of biosurfactant by Pseudomonas aeruginosa UCP 0992. Colloids and Surfaces B. Biointerfaces, v. 79, p. 174-183, 2010.

TULEVA, B.K.; IVANOV, G.R.; CHRISTOVA, N.E. Biosurfactant production by a new Pseudomonas putida strain. Zeitschrift für Naturforschung, v.57, p. 356-360, 2002. 